\title{
Valores econômicos para as características de produção de leite de búfalas no estado de São Paulo'
}

\section{Leonardo de Oliveira Seno ${ }^{2}$, Vera Lúcia Cardoso ${ }^{3}$, Humberto Tonhati ${ }^{4}$}

\author{
${ }^{1}$ Parte do trabalho de Mestrado do primeiro autor. Bolsista do CNPq. \\ 2 Doutorando em Zootecnia, Faculdade de Ciências Agrárias e Veterinárias da UNESP, campus de Jaboticabal, SP, Brasil. \\ 3 APTA REGIONAL Ribeirão Preto, SAA/SP. \\ ${ }^{4}$ Departamento de Zootecnia da FCAV-UNESP, Jaboticabal.
}

RESUMO - Este estudo foi realizado com o objetivo de calcular valores econômicos para as produções de leite (PL), gordura (PG) e proteína (PP) em um sistema de produção de bubalinos leiteiros do estado de São Paulo. Foi desenvolvido um modelo bioeconômico para cálculo do desempenho produtivo, das receitas e dos custos de um rebanho comercial com produção de leite a pasto, suplementação com volumoso na seca e com concentrado durante todo o ano, de acordo com a produção de leite. Os valores econômicos foram calculados pela diferença marginal no lucro anual da fazenda, resultante da mudança em uma unidade da característica, mantendo-se as demais constantes. Foram analisados dois sistemas com diferentes objetivos de seleção: leite - produção de leite para venda ao laticínio; mozarela - produção de leite para fabricação (na própria fazenda) e venda de mozarela. Foram realizadas análises de sensibilidade para avaliar o impacto da mudança nos preços do concentrado, do leite e da mozarela sobre os valores econômicos das características estudadas. Os valores econômicos (R \$) para as produções de leite, gordura e proteína no sistema leite foram, respectivamente, 0,$71 ;-0,74$ e - 0,82 e, para o sistema mozarela, 3,05; 18,66 e 54,38 e indicam que, na política de pagamento vigente, a seleção para a produção de gordura e proteína não é desejável em sistemas de produção cujo objetivo exclusivo é a produção e venda do leite. A agregação da produção de mozarela ao processo produtivo desses sistemas poderia ser economicamente interessante, desde que houvesse a disponibilidade de recursos financeiros.

Palavras-chave: bubalinos, modelagem, mozarela, produção de gordura, produção de proteína

\section{Economic values for milk production traits of dairy buffaloes in São Paulo State}

\begin{abstract}
This study was aimed at calculating the economic values for milk (MY), fat (FY) and protein (PY) yields for a dairy buffalo production system in São Paulo State. The performance, revenues and costs were estimated based on a bioeconomic model developed for a herd of dairy buffaloes raised in a grazing system, with roughage supply during the dry season and concentrate throughout the year. Economic values were calculated from the marginal difference of annual profit resulting from the increase of one unity of the trait, keeping the others constant. Two different commercial systems were considered: 1) The milk production is sold to industry (MILK) and 2) The milk is used to produce mozzarella cheese on the farm (MOZZARELLA). Sensitivity analyses were carried out to evaluate the impact of changes in concentrate, milk and mozzarella prices on the economic values. The economic values of MY, FY and PY respectively in the MILK and in the MOZZARELLA system were $\mathrm{R} \$ 0.71 ; \mathrm{R} \$-0.74$ and $\mathrm{R} \$-0.82$ and $\mathrm{R} \$ 3.05 ; \mathrm{R} \$ 18.66$ and $\mathrm{R} \$ 54.38$. These results suggest that under the current payment policy it is not desirable to improve fat and protein yields when the revenues are based on selling the milk production. The production of mozzarella on the farm may be economically interesting to these systems but depends on availability of financial resources for that investment.
\end{abstract}

Key Words: buffaloes, fat production, modelling, mozzarella, protein production

\section{Introdução}

O aumento da demanda de derivados de leite de búfala nas últimas décadas valorizou a espécie bubalina na pecuária leiteira mundial. Os produtores brasileiros notaram o potencial de mercado e passaram a investir na bubalinocultura. Basicamente, os investimentos foram aplicados em melhorias nas condições e/ou práticas de manejo, que resultaram em melhor desempenho das características produtivas e reprodutivas. Todavia, por ser uma atividade relativamente recente, ainda não foi possível obter grau mínimo de conscientização e organização para o desen- 
volvimento de um programa de melhoramento genético. Algumas iniciativas foram tomadas por parte de Universidades junto à Associação Brasileira de Criadores de Búfalos (ABCB), no sentido de desenvolver um programa de melhoramento genético de búfalos leiteiros, porém, sem sucesso. Isto se deve às dificuldades de execução de um programa de controle sistemático, tanto das informações de desempenho quanto de genealogia, um dos principais entraves no planejamento de um programa de melhoramento genético de búfalos leiteiros.

A Região Sudeste constitui o mercado de queijo de búfala mais competitivo do Brasil. Nesta região, a bubalinocultura é voltada quase que totalmente para a produção de leite, destinada ao processamento de derivados, principalmente mozarela. Atualmente, a seleção de bubalinos é praticada empiricamente, tornando importante a implementação de ferramentas que auxiliem os produtores de búfalos leiteiros no processo de seleção. Entre essas ferramentas, incluem-se programas de controle leiteiro, avaliação genética de animais e uso de índices de seleção combinando as características com vistas a maiores retornos econômicos de acordo com as circunstâncias de mercado e de produção.

A ausência de bonificação para os componentes do leite, somada à aplicação de práticas de seleção empíricas, pode levar a ganhos genéticos menores ou mesmo inexistentes para as características de interesse. Segundo Duarte et al. (2001), a adoção de uma política de pagamento diferenciado ao produtor de leite com maiores porcentagens de gordura e proteína poderia incentivar os bubalinocultores a intensificarem a seleção de animais produtores de leite com adequada porcentagem desses constituintes.

Em programas de seleção orientados economicamente, as características a serem melhoradas constituem o objetivo de seleção, também conhecido como valor agregado, definido por Hazel (1943) como o somatório dos valores genéticos aditivos das diferentes características, ponderados pelos seus respectivos valores econômicos. Na definição de objetivos de seleção, utilizam-se os valores econômicos das características, definidos como a diferença marginal no lucro anual de uma propriedade, resultante do aumento em uma unidade de uma característica, supondo-se que as outras se mantenham inalteradas (Groen et al., 1997). Os valores econômicos são fundamentais na determinação da direção e da importância relativa das características e são necessários para estabelecer os ponderadores do índice de seleção (Veerkamp, 1998).

As metodologias para a obtenção de valores econômicos para diferentes características de acordo com as circunstâncias de produção e de mercado têm sido estudadas exaus- tivamente (Brascamp et al., 1985; Smith et al., 1986; Groen, 1988; Groen, 1989a,b; Groen et al., 1997; Pieters et al., 1997).

De acordo com revisão feita por Groen et al. (1997), a principal ferramenta para derivar valores econômicos é a modelagem, com equações de lucro (profit functions) ou modelos bioeconômicos, que basicamente não diferem entre si. A equação de lucro é um modelo de equação única em que os valores econômicos são obtidos pela derivação parcial. Os modelos bioeconômicos são compostos de equações múltiplas e podem ser aplicados em situações onde há informações de desempenho do rebanho e dos custos e das receitas do sistema de produção ou, então, em sistemas simulados. Os valores econômicos são derivados pela análise da reação às mudanças no mérito genético dos animais para determinada característica, sem alterar as outras, possibilitando a aplicação de diferentes preços, níveis e tamanhos do sistema de produção.

Este trabalho foi realizado com o objetivo de calcular valores econômicos para as produções de leite, gordura e proteína em um sistema de produção de bubalinos leiteiros do estado de São Paulo.

\section{Material e Métodos}

Um modelo bioeconômico foi desenvolvido com o auxílio de planilhas Microsoft ${ }^{\circledR}$ Excel $^{\circledR} 2000$ para o cálculo do desempenho produtivo, das receitas e dos custos, bem como dos valores econômicos para as características produção de leite, gordura e proteína de um sistema de produção de bubalinos leiteiros. Considerou-se um rebanho comercial composto por animais da raça Murrah e seus mestiços. O desempenho das características produtivas foi calculado por ordem e estádio de lactação, considerando os resultados obtidos por Faria et al. (2002) para os grupos genéticos.

Supôs-se que as búfalas em lactação foram mantidas em pastagem de Brachiaria decumbens com suplementação de mistura de cana-de-açúcar e uréia durante o período da seca (maio a outubro), além de sal mineral ad libitum. Assumiu-seo fornecimento diário individual de $1 \mathrm{~kg}$ de concentrado: $3 \mathrm{~kg}$ de leite produzido, de acordo com a produção de leite no dia do controle. As fêmeas nãolactantes foram mantidas nas mesmas condições de pastejo recebendo suplementação mineral ad libitum no cocho. Nos 30 dias do pré-parto, receberam suplementação com volumoso e concentrado $(0,5 \mathrm{~kg}$ por dia), de acordo com a estação do ano, semelhante à fornecida para as búfalas em lactação.

A ordenha (mecânica) foi realizada duas vezes ao dia na presença do bezerro para facilitar a descida do leite. 
Assumiu-se uma distribuição de partos no decorrer do ano referente a um sistema real de produção da região de São Carlos sem sincronização do estro e com acasalamento das fêmeas, por monta natural, na proporção de um touro para 30 fêmeas.

Os pesos médios das fêmeas (Tabela 1) nas diferentes classes de parição foram obtidos da literatura (Baruselli et al., 1993).

As receitas e os custos envolvidos referem-se exclusivamente ao processo de produção de leite na fazenda, pois foram ignorados os processos de criação de bezerros e produção de novilhas para reposição.

Os preços dos produtos e dos componentes de produção (Tabela 1) foram obtidos em relatórios nacionais de estatísticas econômicas especializadas (Anualpec, 2004; IEA, 2004) e de laticínios que processam leite de búfala,

Tabela 1 - Parâmetros biológicos e preços dos componentes de produção utilizados para descrever o sistema de produção de bubalinos leiteiros na situação inicial

Table 1 - Biological parameters and prices of production components used to describe the buffalo milk production system in the initial situation

\begin{tabular}{lr}
\hline Parâmetro & Médi \\
Parameter & Mean \\
\hline
\end{tabular}

Número de fêmeas

100

Number offemales

Produção de leite por lactação $(\mathrm{kg})$

$1.188,50$

Lactation milk production $(\mathrm{kg})$

Gordura do leite (\%)

6,89

Fat milk

Proteína do leite (\%)

3,58

Protein milk

Peso vivo da fêmea - 1a cria (kg)

$575^{1}$

Live weight $1^{\text {st }}$ lactation cows

Peso vivo da fêmea - 2- cria (kg)

Live weight $2^{\text {nd }}$ lactation cows

Peso vivo da fêmea - 3 a cria $(\mathrm{kg})$

Live weight $3^{\text {rd }}$ lactation cows

\begin{tabular}{|c|c|}
\hline $\begin{array}{l}\text { Componente de produção } \\
\text { Production component }\end{array}$ & $\begin{array}{r}\text { Preço }(\mathrm{R} \$) \\
\text { Price }(R \$)\end{array}$ \\
\hline Leite (kg) & $0,80^{2}$ \\
\hline Milk $(k g)$ & \\
\hline Mozarela (kg) & $16,00^{2}$ \\
\hline $\begin{array}{l}\text { Mozzarella } \\
\text { Cana-de-açúcar (kg MS) }\end{array}$ & $0,055^{3}$ \\
\hline $\begin{array}{l}\text { Sugar cane (kg DM) } \\
\text { Brachiaria decumbens (kg MS) }\end{array}$ & $0,011^{3}$ \\
\hline $\begin{array}{l}\text { Brachiaria decumbens ( } k g D M) \\
\text { Concentrado (kg MS) }\end{array}$ & $0,780^{4}$ \\
\hline $\begin{array}{l}\text { Concentrate }(\mathrm{kg} D M) \\
\text { Sal mineral }(\mathrm{kg})\end{array}$ & $3,770^{4}$ \\
\hline $\begin{array}{l}\text { Mineral salt }(\mathrm{kg}) \\
\text { Uréia }(\mathrm{kg})\end{array}$ & $1,250^{4}$ \\
\hline Urea $(\mathrm{kg})$ & \\
\hline
\end{tabular}

Fontes: ${ }^{1}$ Baruselli et al. (1993), ${ }^{2}$ Laticínio White Milk, ${ }^{3}$ Anualpec (2004), 4 IEA (2004).

Sources: ${ }^{1}$ Baruselli et al., (1993), ${ }^{2}$ White Milk dairy industry, ${ }^{3}$ Anualpec (2004), ${ }^{4}$ IEA (2004).

Taxa de câmbio (Exchange rate): US\$ 1,00: R $\$ 2,70$. adotando-se como referência o ano de 2004. Os custos de formação e manutenção de pastagens e forrageiras foram calculados com base em planilhas de custo apresentadas no Anualpec (2004).

Os custos e as receitas foram calculados considerando dois sistemas distintos. No sistema leite, assumiu-se que todo o leite era vendido para um laticínio especializado em processamento de leite de búfala. No sistema mozarela, supôs-se a existência de um laticínio na propriedade para produção e comercialização da mozarela.

As receitas consideradas neste estudo referem-se às produções de leite (PL) e de mozarela (PM), em kg. Outras fontes de receita relacionadas à venda de animais de descarte para o abate e a produção não foram consideradas. $\mathrm{O}$ valor obtido com a venda do leite foi calculado exclusivamente pelo seu volume e o obtido com a venda de mozarela se refere ao preço de venda do produto no atacado.

Os cálculos das produções anuais de leite, gordura e proteína do sistema de produção foram realizados com base na distribuição de partos, considerando o número de animais em lactação em cada mês, de acordo com seu estádio de lactação e com a ordem de parição (Seno, 2005). O rendimento da mozarela (PM), em kg, foi estimado por meio da equação descrita por Altiero et al. (1989):

$$
\mathrm{PM}(\mathrm{kg})=\mathrm{PL}(\mathrm{kg}) * \frac{[(3,5 * \mathrm{PP}(\%))+((1,23 * \mathrm{PG}(\%))-0,88)]}{100}
$$

em que PL, PP e PG são as produções de leite e as porcentagens de gordura e proteína do leite, respectivamente.

Os custos variáveis foram definidos como aqueles influenciados pelo nível de produção do animal, enquanto os custos fixos foram aqueles independentes do nível de produção do rebanho.

No sistema leite, os custos variáveis foram os custos com alimentação das fêmeas (não-lactantes e em lactação), ao passo que, no sistema mozarela, além dos custos variáveis referentes ao processo da produção de leite, consideraram-se os custos com a embalagem do produto. Os custos fixos foram manutenção e depreciação das pastagens, mão-de-obra envolvida na ordenha e manutenção e depreciação da ordenhadeira mecânica.

No sistema mozarela, foram considerados ainda os custos de mão-de-obra, depreciação e manutenção dos equipamentos do laticínio e de armazenamento da mozarela.

Os custos com alimentação foram calculados pela estimativa dos requisitos de energia para as funções metabólicas: mantença, crescimento em primíparas e lactação (leite, gordura e proteína), baseadas em resultados obtidos com búfalos leiteiros por Zicarelli (2001) na Itália. 
As exigências de energia foram obtidas utilizando-se as fórmulas:

Mantença $=1,4 \mathrm{UFL}+(0,6 \mathrm{UFL} *(\mathrm{PV} / 100))$; e

Crescimento (em novilhas) $=4,5$ UFL $*$ GPD.

em que UFL = unidade alimentar para a produção de leite (Demarquilly et al., 1996), equivalente a 1,7 mcal de energia líquida (EL); PV = peso vivo do animal; e GPD = ganho de peso diário. Neste estudo, utilizou-se GPD de $0,33 \mathrm{~kg} /$ dia nas búfalas primíparas.

Os cálculos das exigências de energia para a lactação foram feitos da seguinte forma: aplicou-se a fórmula de Di Palo (1992), citado por Zicarelli (2001), para obtenção da produção de leite corrigido para energia $(\mathrm{ECM})$ : $\mathrm{ECM}=$ PMLD $(k g) *((($ PMGD $(\mathrm{g})-40)+(\operatorname{PMPD}(\mathrm{g})-31)) *$ $0,01155)+1)$, em que PMLD, PMGD e PMPD são as produções médias diárias para as características produtivas (leite, gordura e proteína, respectivamente); e multiplicou-se a produção corrigida (ECM) por 0,44 UFL, obtendo-se, assim, o total necessário de energia líquida.

As informações sobre a composição dos alimentos (MS (\%), PB (\%) e NDT (\%)) utilizados nos cálculos (Tabela 2) foram obtidas nas literaturas nacional (Valadares Filho, 2000) e internacional (Fox et al., 2000) e a partir de dados obtidos a campo.

Considerou-se que a ingestão média de MS (IMS) das búfalas foi de $2 \%$ do peso vivo.

Os valores econômicos (VE) foram obtidos pela diferença marginal da receita líquida anual, sem alterar as demais características, de acordo com o interesse da seleção de maximizar o lucro (receita - custo) para um número fixo de animais em um sistema (Groen et al., 1997).

$\mathrm{VE}=[\delta($ receita anual $)-\delta($ custo anual $)]$, em que $\delta$ é a diferença marginal (após seleção - antes da seleção).

Foram realizadas análises de sensibilidade para avaliar o impacto de possíveis mudanças nos preços do concentrado, do leite e da mozarela sobre os valores econômicos

Tabela 2 - Composição (\%) dos alimentos da dieta Table 2 - Composition (\%) of feeds used in the diet

\begin{tabular}{lccc}
\hline Alimento & MS & PB & NDT \\
Feed component & $D M$ & $C P$ & $T D N$ \\
\hline $\begin{array}{l}\text { Concentrado } \\
\text { Concentrate }\end{array}$ & $88,00^{2}$ & $20,00^{2}$ & $72,30^{2}$ \\
$\begin{array}{l}\text { Cana-de-açúcar } \\
\text { Sugar cane }\end{array}$ & $24,16^{1}$ & $4,21^{1}$ & $65,39^{1}$ \\
B. decumbens & $32,75^{1}$ & $7,26^{1}$ & $55,00^{3}$ \\
\hline
\end{tabular}

Fontes: ${ }^{1}$ Valadares Filho (2000), ${ }^{2}$ Dados obtidos a campo, ${ }^{3}$ Fox et al. (2000).

Sources: ${ }^{1}$ Valadares Filho (2000), ${ }^{2}$ On farm data, ${ }^{3}$ Fox et al. (2000). das características estudadas. Para isso, procedeu-se a variações no preço do concentrado, do leite e da mozarela em $\pm 20 \%$ e $\pm 40 \%$ do valor inicial.

\section{Resultados e Discussão}

Na situação inicial, a produção anual de leite foi de $91.166,98 \mathrm{~kg}$ (sistema leite) e a de mozarela, de $18.170,76 \mathrm{~kg}$ (sistema mozarela). As receitas anuais observadas foram de $\mathrm{R} \$ 72.933,58$ para o sistema leite e de $\mathrm{R} \$ 290.732,18$ para o sistema mozarela. Os custos com alimentação, reprodução e ordenha foram, respectivamente, $\mathrm{R} \$ 31.722,88, \mathrm{R} \$ 6.765,27$ e R\$ 19.519,14 no sistema leite. Dos componentes de custo considerados no sistema leite, os custos com alimentação das fêmeas foram os mais importantes e representaram 54\% dos custos totais de produção de leite. No sistema mozarela, além dos custos com a produção de leite, foram computados os custos adicionais de fabricação de mozarela, de R \$ 69.301,44. Foram obtidos, assim, lucros de R\$ 14.926,30 e R\$ 163.423,46 para os sistemas leite e mozarela, respectivamente.

A princípio, estes resultados sugerem que a produção de leite para fins de processamento de mozarela é bem mais vantajosa economicamente que a produção de leite para a entrega em laticínios especializados.

No sistema leite, os valores econômicos para as produções de gordura e proteína foram negativos (Tabela 3), em decorrência da falta de uma política de pagamento diferenciado para os componentes do leite, indicando que, em virtude do preço pago pelo volume de leite, não é vantajosa a seleção para estas características. Pesquisas realizadas no Brasil (Madalena, 2000; Vercesi Filho et al., 2000; Martins et al., 2003; Cardoso et al., 2004) também apontam valores econômicos negativos para gordura e proteína para sistemas de produção de gado leiteiro. O valor econômico da produção de proteína foi menor que o de produção de gordura, o que contraria outros resultados de literatura obtidos para sistemas de produção com bovinos leiteiros. Isso pode ter ocorrido pelo fato de o teor de proteína ser muito mais baixo em relação ao teor de gordura, no leite dos bubalinos.Assim, para se obter aumento de um quilograma de proteína na produção anual do sistema, seria necessário aumento proporcionalmente maior desta característica.

No sistema mozarela, os valores econômicos para PL, PG e PP foram, respectivamente, $\mathrm{R} \$ 3,05 ; \mathrm{R} \$ 18,66 \mathrm{e}$ $\mathrm{R} \$ 54,38$. Neste caso, a importância econômica dos componentes é muito grande se comparada ao sistema de venda de leite, uma vez que o rendimento de mozarela é afetado pelo teor dos constituintes. Entre esses constituintes, a proteína foi o que apresentou o maior valor econô- 
Tabela 3 - Valores econômicos (VE), em R\$, para as características de produção de leite (PL), gordura (PG) e proteína (PP) nos sistemas leite e mozarela na situação básica e após mudança nos preços do concentrado, do leite e da mozarela ( \pm 20 e $40 \%)$

Table 3 - Economic values (EV), expressed in R\$, of milk (MY), fat (FY) and protein (PY) yields, for MILK and MOZZARELLA systems, in the basic situation and after changing the concentrate, milk and mozzarella prices ( \pm 20 and $40 \%$ )

\begin{tabular}{|c|c|c|c|c|c|c|}
\hline & \multicolumn{3}{|c|}{$\begin{array}{l}\text { Leite } \\
\text { Milk }\end{array}$} & \multicolumn{3}{|c|}{$\begin{array}{l}\text { Mozarela } \\
\text { Mozzarella }\end{array}$} \\
\hline & $\begin{array}{l}\mathrm{VE}_{\mathrm{PL}} \\
E V_{M Y}\end{array}$ & $\begin{array}{l}\mathrm{VE}_{\mathrm{PG}} \\
E V_{F Y}\end{array}$ & $\begin{array}{l}\mathrm{VE}_{\mathrm{PP}} \\
E V_{P Y}\end{array}$ & $\begin{array}{l}\mathrm{VE}_{\mathrm{PL}} \\
E V_{M Y}\end{array}$ & $\begin{array}{l}\mathrm{VE}_{\mathrm{PG}} \\
E V_{F Y}\end{array}$ & $\begin{array}{l}\mathrm{VE}_{\mathrm{PP}} \\
E V_{P Y}\end{array}$ \\
\hline & \multicolumn{6}{|c|}{$\begin{array}{l}\text { Situação básica } \\
\text { Basic situation }\end{array}$} \\
\hline & 0,71 & $-0,74$ & $-0,82$ & 3,05 & 18,66 & 54,38 \\
\hline Variação (\%) & \multicolumn{6}{|c|}{ Mudança no preço do concentrado } \\
\hline Change (\%) & \multicolumn{6}{|c|}{ Change in concentrate price } \\
\hline-40 & 0,75 & $-0,44$ & $-0,49$ & 3,09 & 18,96 & 54,71 \\
\hline-20 & 0,73 & $-0,59$ & $-0,65$ & 3,07 & 18,81 & 54,54 \\
\hline+20 & 0,69 & $-0,89$ & $-0,98$ & 3,03 & 18,51 & 54,22 \\
\hline+40 & 0,67 & $-1,03$ & $-1,14$ & 3,01 & 18,36 & 54,05 \\
\hline & \multicolumn{3}{|c|}{$\begin{array}{l}\text { Mudança no preço do leite } \\
\text { Change in milk price }\end{array}$} & \multicolumn{3}{|c|}{$\begin{array}{c}\text { Mudança no preço da mozarela } \\
\text { Change in mozzarella price }\end{array}$} \\
\hline-40 & - & - & - & 1,78 & 10,79 & 31,98 \\
\hline-20 & 0,55 & $-0,74$ & $-0,82$ & 2,41 & 14,72 & 43,18 \\
\hline+20 & 0,87 & $-0,74$ & $-0,82$ & 3,69 & 22,60 & 65,58 \\
\hline+40 & 1,03 & $-0,74$ & $-0,82$ & 4,33 & 26,53 & 76,78 \\
\hline
\end{tabular}

mico, o que era esperado dada a sua importância na fabricação de queijos em geral.

De modo geral, mudanças que acarretaram aumento nas receitas (aumento no preço do leite ou da mozarela e redução no preço dos concentrados) resultaram no aumento dos valores econômicos e vice-versa (Figura 1).

O valor econômico da produção de leite no sistema leite foi pouco afetado pelas mudanças no preço do concentrado, enquanto, no caso das produções de gordura e proteína, esse efeito foi bem pronunciado, com variações superiores a 100\%, em decorrência das maiores exigências nutricionais para a produção desses constituintes do leite.

No sistema mozarela, a mudança no preço do concentrado não promoveu grandes alterações nos valores econômicos das três características estudadas, em virtude do alto valor agregado obtido com a fabricação de mozarela (Figura 1c).

A mudança no preço do leite afetou somente o valor econômico da produção de leite, uma vez que seu preço não incluiu um valor adicional para os componentes (gordura e proteína). A redução no preço do leite ocasionou diminuição da eficiência econômica do sistema de produção. Redução de $40 \%$ no preço do leite faria com que o sistema se tornasse antieconômico, pois a receita obtida com a venda do leite seria inferior aos custos de produção (Figura 1b).
Em relação às mudanças no preço da mozarela, observou-se que os valores econômicos de todas as características foram positivos mesmo após reduções maiores no preço do produto. O impacto da mudança do preço da mozarela sobre o valor econômico da produção de proteína (Figura 1d) foi muito maior em comparação aos valores econômicos das demais características.

Uma das vantagens do uso de modelos bioeconômicos é a possibilidade de se avaliar facilmente o impacto de mudanças de cenários nos valores econômicos das características e recalcular esses valores caso seja neces sário.

Em breve, políticas de pagamento diferenciado para características de qualidade do leite poderão ser implantadas no País para o leite bovino, o que pode refletir futuramente nas políticas de pagamento do leite de búfalas, no entanto, os produtores deverão estar preparados e informados sobre as ferramentas disponíveis para melhorar a qualidade do leite e a lucratividade dos seus rebanhos, inclusive o melhoramento genético. Desde que haja um programa de avaliação genética de reprodutores para as características abordadas neste estudo, a escolha de touros pode ser feita com base em índices de seleção que combinem essas três características, de modo a proporcionar o melhor retorno econômico para os produtores de acordo com os objetivos dos seus rebanhos. 


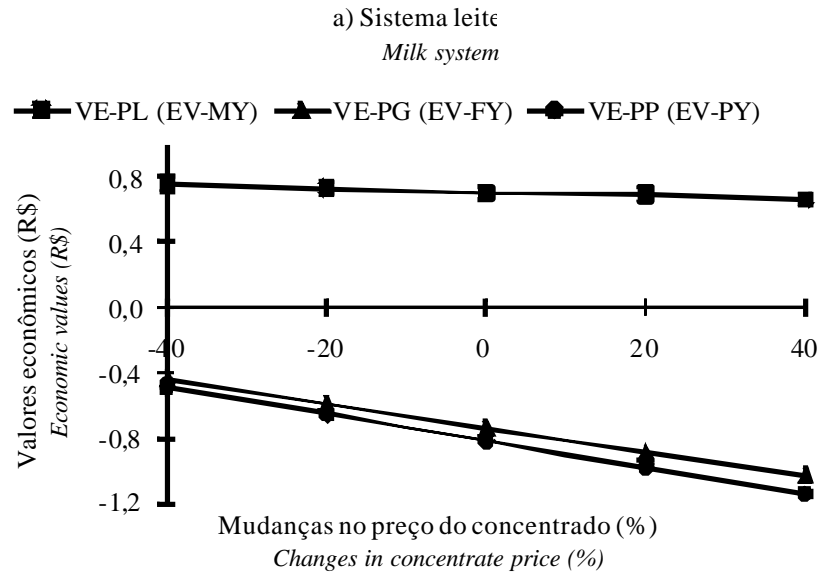

b) Sistema leite Milksystem

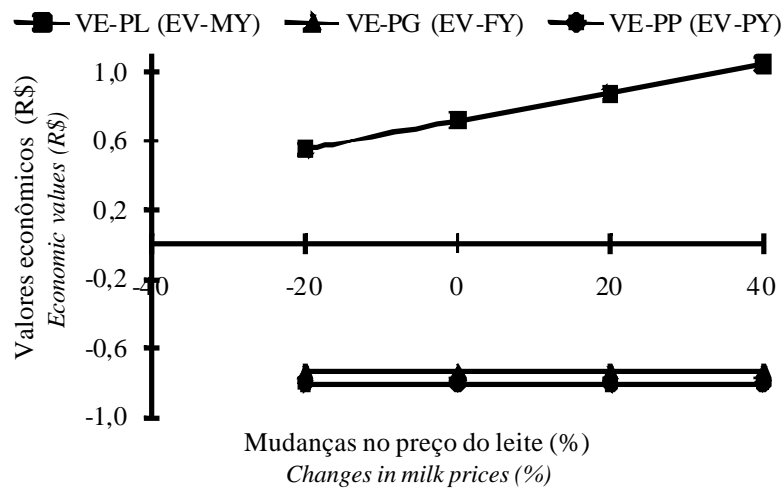

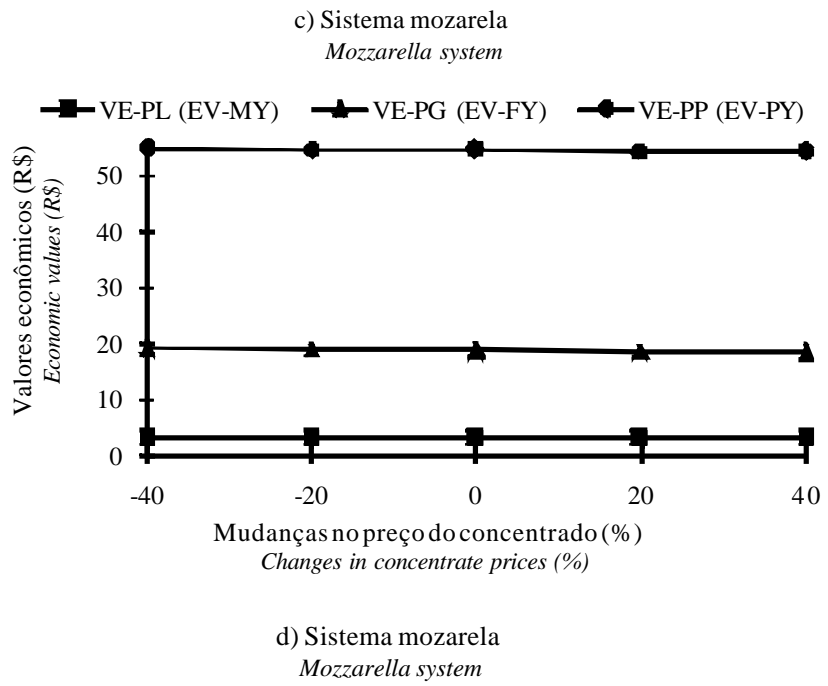

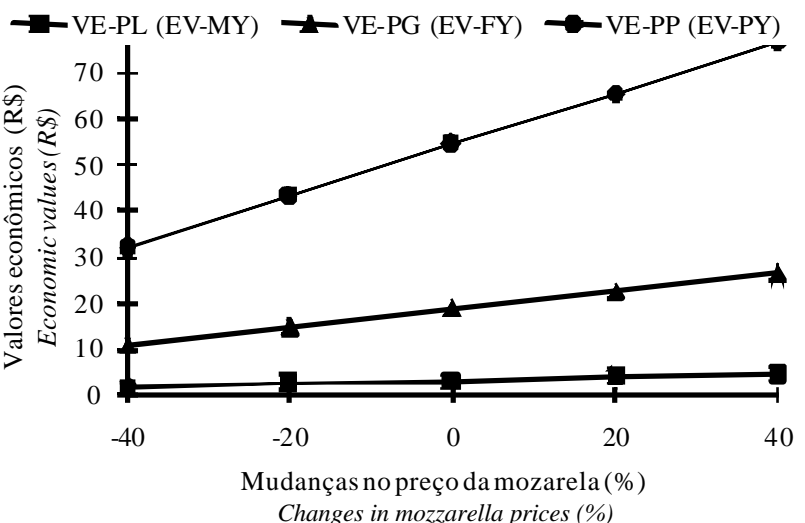

Figura 1 - Efeito das mudanças nos preços do concentrado, leite e mozarela ( \pm 20 e $40 \%$ ) sobre os valores econômicos (VE) das características de produção de leite (PL), gordura (PG) e proteína (PP) nos sistemas leite (a e b) e mozarela (c e d).

Figure 1 - Effect of changes ( \pm 20 and $40 \%$ ) in concentrate, milk and mozzarella prices on the economics values (EV) of milk (MY), fat (FY) and protein (PY) yields for milk ( $a$ e b) and mozzarella ( $c$ and d) systems.

\section{Conclusões}

Os resultados obtidos neste estudo comprovaram que, na política vigente de pagamento de leite, a inclusão de características de produção de gordura e proteína em objetivos de seleção para sistemas de produção de bubalinos leiteiros cuja finalidade é a venda do leite não é economicamente vantajosa.

Os valores econômicos das características de produção de gordura e proteína obtidos no sistema mozarela indicam que a agregação da produção de mozarela ao processo produtivo dos sistemas de produção de bubalinos leiteiros é interessante economicamente, tendo em vista a importância dessas características no rendimento do produto.

\section{Agradecimento}

À Agência Paulista de Tecnologia dos Agronegócios (APTA), da Secretaria de Agricultura e Abastecimento do
Estado de São Paulo (APTA Regional - Ribeirão Preto), pelo apoio no desenvolvimento deste trabalho. Ao Laticínio White Milk e à fazenda Santa Eliza, pela valiosa disponibilidade das informações, fundamentais para o desenvolvimento deste trabalho. Ao CNPq, pela concessão da bolsa de mestrado ao primeiro autor. À FAPESP, pelo suporte financeiro.

\section{Literatura Citada}

ALTIERO, V.; MOIO, L.; ADDEO, F. Previsione della resa in mozzarella sulla base del contenuto in grasso e proteine del latte di bufala. Scienza e Tecnica Lattiero-Casearia, v.40, p.425-433, 1989

ANUALPEC. Anuário da pecuária brasileira. São Paulo: FNP Consultoria e Comércio, 2004. 304p.

BARUSELLI, P.S.; OLIVEIRA, J.F.S.; MENDES, M.L.M. et al. Diagnóstico da bubalinocultura do Vale do Ribeira. Campinas: CATI, 1993. 16p. (Documento Técnico, 94).

BRASCAMP, E.W.; SMITH, C.; GUY, D.R. Derivation of economic weights from profit equation. Animal Production, v.40, p.175-180, 1985. 
CARDOSO, V.L.; NOGUEIRA, J.R.; VERCESI FILHO, A.E. et al. Objetivos de seleção e valores econômicos de características de importância econômica para um sistema de produção de leite a pasto na Região Sudeste. Revista Brasileira de Zootecnia, v.33, n.2, p.320-327, 2004

DEMARQUILLY, C.; FAVERDIN, P.; GEAY, Y. et al. Bases rationnelles de l'alimentation des ruminants. Disponível em: <http://www.inra.fr/productions-animales/hs 1996/cd96h. htm>. Acesso em: 9/2/2005.

DI PALO, R. Produzione lattea nella bufala con diete tradizionali e con l'impiego di acidi grassi. Naples: University of Naples Federico II, 1995. Thesis (PhD) University of Naples, Naples, Italy, 1992. In: ZICARELLI, L. (Ed.) Nutrition in dairy buffaloes. Naples: University of Naples Federico II, 2001.p. 66

DUARTE, J.M.C.; TONHATI, H.; CERON-MUÑOZ, M.F. et al. Efeitos ambientais sobre a produção no dia do controle características físico-químicas do leite em um rebanho bubalino no estado de São Paulo, Brasil. Revista do Instituto de Laticínios Cândido Tostes, v.56, n.322, p.17-20, 2001.

FARIA, M.H.; TONHATI, H.; CERON-MUÑOZ, M.F. et al Características físico-químicas do leite de búfalas ao longo da lactação. Revista do Instituto de Laticínios Cândido Tostes, v.57, n.324, p.3-7, 2002.

FOX, D.G.; TYLUTKI, T.P.; van AMBURGH, M.E. et al. The net carbohydrate and protein system for evaluation herd nutrition and nutrient excretion: The Cornell University Nutrient Management Planning System - CNCPS version 4.0. Cornell: Cornell Universty, 2000. 237p.

GROEN, A.F. Derivation of economic values in cattle breeding: a model at farm level. Agricultural Systems, v.27, p.195-213, 1988.

GROEN, A.F. Economic values in cattle breeding. I. Influence of production circunstances in situations without output limitations. Livestock Production Science, v.22, p.1-16, 1989a.

GROEN, A. F. Economic values in cattle breeding. II. Influence of production circunstances in situations with output limitations. Livestock Production Science, v.22, p.17-30, 1989b.

GROEN, A.F.; STEINE, T.; COLLEAU, J.J. et al. Economic values in dairy cattle breeding, with special reference to functional traits. Livestock Production Science, v.49, p.1-21, 1997.
HAZEL, L.N. The genetic basis for constructing selection indexes. Genetics, v.28, p.476-490, 1943.

INSTITUTO DE ECONOMIA AGRÍCOLA - IEA. [2004]. Disponível em: <http://www.iea.sp.br>. Acesso em: 22/11/2004.

MADALENA, F.E. Valores econômicos para a seleção de gordura e proteína do leite. Revista Brasileira de Zootecnia, v.29, n.3, p.678-684, 2000.

MARTINS, G.A.; MADALENA, F.E.; BRUSCHI, J.H. et al. Objetivos econômicos de seleção de bovinos de leite para Fazenda Demonstrativa na Zona de Mata de Minas Gerais. Revista Brasileira de Zootecnia, v.32, n.2, p.304-314, 2003.

PIETERS, T.; CANAVESI, F.; CASSANDRO, M. et al. Consequences of differences in princing systems between regions on economic values and revenues of a national dairy cattle breeding scheme in Italy. Livestock Production Science, v.49, p.23-32, 1997.

SENO, L.O. Valores econômicos para as características de produção de leite de búfalos (Bubalus bubalis) no Estado de São Paulo. Jaboticabal: Universidade Estadual Paulista, 2005. 43p. Dissertação (Mestrado em Genética e Melhoramento Animal) - Universidade Estadual Paulista, 2005.

SMITH, C.; JAMES, J.W.; BRASCAMP, E.W. On the derivation of economic weights in livestock improvement. Animal Production, v.43, p.545-551, 1986

VALADARES FILHO, S.C. Nutrição, avaliação de alimentos e tabelas de composição de alimentos. In: REUNIÃO ANUAL DA SOCIEDADE BRASILEIRA DE ZOOTECNIA, 37., 2000 Viçosa, MG. Anais... Viçosa, MG: Sociedade Brasileira de Zootecnia, 2000. p.267-340.

VEERKAMP, R.F. Selection for economic efficiency of dairy cattle using information on live weight and feed intake: a review. Journal Dairy Science, v.81, p.1109-1119, 1998.

VERCESI FILHO, A.E.; MADALENA, F.E.; FERREIRA, J.J. et al. Pesos econômicos para seleção de gado leiteiro. Revista Brasileira de Zootecnia, v.29, n.1, p.145-152, 2000.

ZICARELLI, L. Nutrition in dairy buffaloes. Naples: University of Naples Federico II, 2001. 66p. 